\title{
O USO DA LOGÍSTICA REVERSA PARA MINIMIZAR OS IMPACTOS AMBIENTAIS CAUSADOS PELO LIXO ELETRÔNICO
}

\author{
THE USE OF REVERSE LOGISTICS TO MINIMIZE ENVIRONMENTAL IMPACTS \\ CAUSED BY ELETRONIC WASTE
}

\section{Erika Karoline da Silva Reis}

RESUMO: Nos últimos anos, com o grande avanço das inovações tecnológicas e o alto volume gerado de resíduos eletrônicos causam grande preocupação em relação ao meio ambiente. Devido à alta concentração de metais pesados encontrados nesse lixo eletrônico que podem prejudicar o meio ambiente é a saúde humana. Diante desse grande problema mundial. Este artigo através de pesquisa bibliográfica teve como objetivo apresentar os perigos do lixo eletrônico ao meio ambiente, mostrar uma abordagem geral sobre logística reversa e mostrar como a logística reversa através da reciclagem e do reuso pode auxiliar na diminuição dos impactos ambientais causados pelo lixo eletrônico. Em seguida foi aplicado um questionário para identificar o conhecimento da população de Porto Velho sobre o lixo eletrônico é onde eram acostumados a descartar esse tipo de lixo. Diante dos resultados desse questionário, foi proposto a criação de uma cooperativa de reciclagem de resíduos eletrônicos, de modo a mitigar o problema do lixo eletrônico, visto que boa parte da população desconhece a existência da coleta seletiva.

Palavras-chave: Lixo eletrônico. Logística reversa. Meio ambiente.

ABSTRACT: In resent years, with the great advance of technological innovations and the high volume generated of electronic waste cause great concern about the environment. Due to the high concentration of heavy metals found in this electronic waste that can harm the environment is human health. Faced with this great global problem. This work through bibliographical research aimed to resente the dangers of electronic waste to the environment, show a general approach on reverse logistics and show how reverse logistics through recycling and reuse can help reduce the environmental impacts caused by electronic waste. Then a questionnaire was applied to identify the knowledge of the population of Porto Velho about electronic waste, where they were accustomed to discard this type of garbage. In view of the results of this questionnaire, it was proposed the creation of na electronic waste recycling cooperative, in order to mitigate the problem of electronic waste, since a large part of the population is unaware of the existence of selective collection.

Keywords: Electronic waste. Reverse logistic. Environment.

\footnotetext{
1E-mail: erikakaroline_15@hotmail.com
} 


\section{INTRODUÇÃO}

É de conhecimento geral que vivemos na era da tecnologia, onde os seres humanos estão cada vez mais dependentes dos equipamentos eletrônicos. No entanto, quando um aparelho eletrônico se torna obsoleto a maioria das pessoas simplesmente desconhece a maneira correta de como descartar esse resíduo eletrônico e acabam descartando de maneira inadequada, junto ao lixo comum. O descarte incorreto desse lixo eletrônico pode contaminar o solo e água, devido ao seu grande potencial tóxico presente em seus componentes. Com o intuito de evitar esse tipo de problema e dar a destinação correta aos resíduos eletrônicos a Política Nacional de Resíduos Sólido por meio da Lei 13.576 determina que os setores envolvidos com a geração de lixo eletrônico adotem a logística reversa. E se tornem responsável por aquilo que produzem, evitando assim o acumulo de resíduos eletrônicos em locais inapropriados.

Apesar de existir essa lei no país que obriga o fabricante dá a destinação correta. São poucas as empresas que se preocupam com a destinação final dos seus produtos e desconhecem os benefícios que a logística reversa pode trazer para o seu negócio.

De acordo com uma pesquisa feita em 2018 pela Organização das Nações Unidas (ONU), o Brasil é o maior produtor de lixo eletrônico da América latina, o país gera, em média, I,5 milhão de toneladas de resíduos eletrônicos por ano, apesar disso somente 3\% desse lixo recebe o tratamento correto. Enquanto boa parte desse lixo vai parar em lixões ao ar livre contaminando e poluindo o ambiente.

Diante desse cenário, buscou-se fazer uma pesquisa bibliográfica através de artigos e publicações sobre o tema proposto com intuito de responder o seguinte problema de pesquisa. De que forma a aplicação da logística reversa pode auxiliar para diminuir os impactos ambientais causados pelo lixo eletrônico?

\section{LOGÍSTICA DIRETA}

A logística surgiu como artifício de guerra e era relacionada ao transporte e armazenagem, visando sempre ter os recursos certo na hora certa. Com o passar dos anos esse conceito migrou-se para o setor empresarial, visto que era importante se ter um departamento para cuidar da logística onde a demanda crescia em um ritmo muito acelerado. Hoje entendemos a logística como um conjunto de etapas operacionais necessárias para garantir que a empresa cumpra o que promete aos seus clientes. 
Para Novaes o conceito de logística é:

[...]Logística é o processo de planejar, implementar e controlar de maneira eficiente o fluxo e a armazenagem de produtos, bem como os serviços e informações associadas, relativas desde o ponto de origem até o ponto de consumo, com o objetivo de atender aos requisitos do consumidor. (NOVAES,2001, p.36).

Basicamente são quatro as etapas do processo de logística: inicia-se na gestão de compras de insumos para a produção. Depois disso, esses insumos precisam ser armazenados em um local apropriado, onde ficaram disponíveis e em segurança. Esse armazenamento gera o estoque que corresponde a estrutura com ativos que serão utilizados de acordo com cada exigência. Na última etapa depois do requerimento, os insumos se transformam em produtos que serão distribuídos ao seu destino final.

Segundo Rodrigues (2007), a logística direta é um conjunto de atividades direcionadas a agregar valor, otimizando o fluxo de materiais, desde a produção até o consumidor final, garantindo a quantidade certa, de maneira adequada, assegurando sua integridade e atendendo a todas as necessidades dos clientes garantindo que o cliente obtenha o maior proveito da sua compra.

Visto que o processo logístico não se encerra com a entrega do produto ao consumidor final, as empresas necessitam da logística reversa para completar o ciclo do processo logístico, através de canais reversos com o objetivo de reciclar, reaproveitar ou reinserir esses bens novamente na cadeia produtiva.

\section{LOGÍSTICA REVERSA}

A logística reversa por ser tratar de um tema novo, ainda é pouco abordado. Entretanto, podemos entender a logística reversa como o processo que planeja e controla o fluxo das informações referentes ao retorno dos produtos produzidos após sua venda. Ou seja, consiste no fluxo reverso pelo qual a mercadoria através da reciclagem retornar de volta para a empresa.

Segundo Chaves e Martins (2005), foi nos anos 90 que surgiram as primeiras abordagens sobre o assunto, destacando o aumento da preocupação com questões ambientais, legislação nessa área, órgãos de fiscalização e a preocupação com perdas por parte das empresas, esses aspectos contribuíram para a evolução do tema.

Antigamente a logística era relacionada apenas ao transporte, armazenagem e distribuição dos produtos, após isso o fabricante não tinha mais responsabilidades nenhuma sobre os produtos 
comercializados. Entretanto, isso começou a mudar devido às legislações mais rígidas voltadas para questões ambientais. Como a Lei 12.305, promulgada em 2 de agosto de 2010, conhecida como PNRS, que obriga as empresas a recolherem e dá a destinação correta os seus resíduos.

Entende-se Logística reversa surgiu através da necessidade de recolher e dar encaminhamento aos produtos de pós-vendas ou pós-consumo, porém, ela não se restringe somente a isso. É uma área muito mais abrangente, que envolve todos os fluxos físicos, toda gestão de materiais e todas as informações inerentes, nos dois sentidos, direto e inverso. (Carvalho, 2002, p.3I). atualmente as empresas estão buscando adequar seus processos produtivos, reconhecem que além de buscar o lucro, é necessário preocupar-se com os recursos naturais e com o retorno dos produtos para reaproveitamento. Além de melhorar a imagem corporativa da empresa, visto que empresas que praticam a sustentabilidade tendem a ser mais requisitada pelos consumidores.

Logística direta e logística reversa podem até parecerem ser a mesma coisa, mas não são. A logística direta refere-se ao fluxo de materiais do ponto de aquisição até chegar ao ponto de consumo. Já a logística reversa consiste num processo de movimentação de mercadorias de seu destino final com objetivo de agregar valor, ou dá a destinação adequada. Que envolve operações relacionadas com a reutilização dos produtos e materiais.

Entende-se que a logística reversa é focada no retorno dos produtos de pós-consumo ao setor produtivo, para o reaproveitamento, com o objetivo de recuperar valor ou dar a destinação correta aos resíduos.

A logística reversa se divide em dois tipos de canais de distribuição reversos, onde ocorre o retorno dos bens de pós-consumo e pós-vendas. No pós-vendas, o produto retorna para a cadeia produtiva antes de passar pelo consumidor final, ou que tenha tido pouco uso, devido a defeitos ou por algum erro.

Leite (2003, p.9) define logística de pós-vendas como:

[...] Especifica área de atuação da logística reversa que se ocupa do planejamento, da operação e do controle do fluxo físico e das informações logísticas correspondentes do bem de pós-venda, sem uso ou com pouco uso, que por diferentes motivos retornam aos diferentes elos da cadeia de distribuição direta, que constituem uma parte dos canais reversos pelos quais fluem esses produtos.

\section{LIXO ELETRÔNICO}


O lixo eletrônico, também conhecido como e-lixo, são resíduos provenientes de materiais eletrônicos como televisões, celulares, computadores, etc. nessa categoria inclui também os produtos da linha branca, como máquinas de lavar, refrigeradores e micro-ondas. Que não possui mais valor, ou se tornaram obsoletos.

Segundo Brasil (20II), foi a partir do século XX que produtos eletrônicos começaram a chegar a países, como o Brasil. Graças à rede mundial de computadores, a Internet que surgiu nos EUA em 1969 durante o projeto da Arpanet na época da guerra fria e que jamais deixou de evoluir, hoje os diferentes tipos de produtos e serviços chegam simultaneamente em velocidade rápida em todo o mundo. Desde então a procura por novos produtos aumentou, e hoje vivemos na era do descartável onde as pessoas substituem rapidamente seus produtos por outros mais novos, gerando uma enorme quantidade de lixo eletrônico que geralmente seu destino final são aterros sanitários ou lixões ao céu aberto. O que aumenta assim, os problemas ambientais e também prejudica a saúde humana (LABIDI, 20II).

Para Celinski et al. (20II), o acelerado avanço tecnológico tem causado obsolescência dos equipamentos eletrônicos num curto espaço de tempo. Oriundo do descarte de aparelhos eletrônicos, como computadores pessoais e celulares, o lixo eletrônico é um problema cada vez mais aparente na sociedade atual. Quando não descartado adequadamente, pode causar sérios danos à saúde e ao meio ambiente.

Segundo Affonso (2008), o lixo eletrônico é considerado uma bomba-relógio, cujo os efeitos vão recair da maneira mais inesperada possível sobre a sociedade.

De acordo com dados da Organização das Nações Unidas (ONU). Cada ser humano no mundo descarta, em média, sete quilos de resíduos eletrônicos todos os anos. Com isso são gerados cerca de 48,9 milhões de toneladas de dispositivos elétricos, o suficiente para cobrir três quartos da linha do Equador com caminhões carregados de 40 toneladas de lixo eletrônico.

Uma questão que está diretamente ligada a esse aumento do lixo eletrônico, é a obsolência programada. Que consiste em uma estratégia das empresas, que programam o tempo de vida útil de seus produtos para que durem menos tempo que a tecnologia permite. Estimulando assim o consumo excessivo.

\section{IMPACTOS AMBIENTAIS}


De acordo com estudo feito em 2017 pela Global e-Waste Monitor, o Brasil é o país da América latina que mais produz lixo eletrônico e fica em sétimo lugar no mundo, ficando atrás apenas da China, Estados Unidos, Japão, Índia, Alemanha e o Reino Unido. Sendo que apenas 3\% desse lixo e coletado. O restante desse lixo acaba sendo descartado de maneira inadequada trazendo enormes prejuízos para ao meio ambiente. Visto que os equipamentos eletrônicos possuem diversas substâncias tóxicas em sua composição, desde elementos químicos simples, a recursos não renováveis e metais pesados. Exemplos destes são: chumbo, mercúrio e cromo. Que mesmo em pequenas quantidades podem causar danos imensuráveis ao meio ambiente.

Para Gonçalves (2007), o chumbo se acumula no meio ambiente e tem efeitos tóxicos agudos e crônicos nas plantas, animais e microrganismos. Outro exemplo é o cádmio, usado como estabilizador de plásticos e nos detectores de infravermelhos e semicondutores, que, por se acumular e ser altamente tóxico, possui um perigo potencial para o meio ambiente. O Mercúrio possui uma quantidade pouco relevante e é encontrado nos telefones celulares e baterias. $O$ cromo outro componente, aplicado em placas de aço como proteção anticorrosiva também é um composto muito tóxico. Que ao serem descartados de maneira inadequada no meio ambiente, com passar dos tempos, esses materiais geram um líquido poluente, de cor escura que contamina o solo.

De acordo com uma reportagem da BBC Brasil em (201I), "Em Gana, foram feitos testes em um centro de reciclagem informal, que mostram que o nível de chumbo, cádmio e outros poluentes encontrados nesses aterros sanitários estão cerca de 50 vezes acima do nível considerado seguro".

Para Ferreira e Ferreira (2008), a poluição ocorre também durante a fabricação dos aparelhos eletroeletrônicos, consequência dos poluentes utilizados. Que em contato com ser humano, pode desenvolver doenças respiratórias, de pele e até mesmo o câncer. Estudos apontam que na fabricação de um computador, são necessárias toneladas de insumo não renovável e uma quantidade absurda de água. Diante disso o primeiro grande impacto do lixo eletrônico é na sua fabricação

Uns dos principais problemas relacionados ao descarte incorreto dos resíduos eletrônicos é a contaminação por metais pesados e seus efeitos. De maneira geral, os impactos ambientais causados pelo lixo eletrônico podem ser divididos em três grandes grupos:

I) Redução do tempo de vida útil dos aterros sanitários:

Equipamentos eletrônicos como computadores, celulares e baterias têm em sua composição, materiais tóxicos que demoram mais de Ioo anos para se decompor, como vidro e o plástico. Quando 
descartados em aterros a céu aberto, aumentam o volume de lixo, reduzem o seu tempo de vida útil e ocorre a emissão de gases para a atmosfera colaborando com o aumento do aquecimento global.

2) Contaminação por metais pesados:

As placas e circuitos elétricos contidos nos aparelhos eletrônicos possuem quantidades enormes de metais pesados, como chumbo e mercúrio. Por se tratar de substâncias altamente poluentes, contaminam o solo e água, dos rios e dos lençóis freáticos.

Cartuchos e toners de impressoras, apesar de aparentemente inofensivos, contém um pó que, ao entrar em contato com fogo, libera o gás metano, que pode causar explosões.

3) Danos à saúde pública:

O descarte incorreto do lixo eletrônico causa danos à saúde da população que vive entorno dos aterros sanitários e aos catadores que buscam nos aterros sanitários materiais para vender ou para o seu consumo.

Segundo Macedo (200o), a eliminação e descarga de todo o lixo eletrônico existente no século XXI é praticamente impossível, porém a reciclagem pode evitar maiores danos ao meio ambiente.

\section{LOGÍSTICA REVERSA NO DESCARTE DO LIXO ELETRÔNICO}

A indústria da tecnologia é uma das que mais colaboram para a poluição do meio ambiente. Diante disso muitas organizações utilizam a logística reversa como artifício para agregarem valor ao seu produto e reduzir os danos ao meio ambiente (LEITE, 2003). Por meio da logística reversa é possível fazer o reaproveitamento e reciclagem do lixo eletrônico, transformando-os novamente em matéria-prima. Além de diminuir os impactos ambientais causado pelo lixo eletrônico, as empresas podem gerar lucros diretos e indiretamente, através do reaproveitamento da matéria-prima. Ao reciclar seus próprios resíduos ou usar materiais reciclados de outras fontes, reduz a necessidade de matéria prima e pode levar à redução do uso de energia e água (BRANDALISE, 2008, p. 44).

Segundo uma matéria publicada no jornal da cidade de Bauru (2012):

[...] de uma tonelada de celulares (sem bateria) é possível extrair até 175 gramas de ouro, o que gera $R \$ 16.667,50$, já que o grama do metal nobre custa $R \$ 95,30$. No entanto, esse processo só é feito em outros países.

Segundo a UNEP (2009), o manuseio adequado do lixo eletrônico pode tanto prevenir danos ambientais graves como recuperar materiais valiosos, especialmente os metais. 
A logística reversa surge como solução para o problema do lixo eletrônico, e através do marketing dessas ações as empresas consegue obter alguns benefícios financeiros. 


\section{POLÍTICA NACIONAL DE RESÍDUOS SÓLIDOS}

A Política Nacional de Resíduos Sólidos é uma lei que foi desenvolvida com base nas experiências de países desenvolvidos. Foi adaptada às necessidades brasileiras e instituída no Brasil em 2 de agosto 2010. Através da lei 12.305/2010, a qual estabelece a responsabilidade compartilhada do descarte de resíduos.

[...] Art. ${ }^{\circ}$ Esta lei institui a Política Nacional de Resíduos sólidos, dispondo sobre seus princípios, objetivos e instrumentos, bem como sobre as diretrizes relativas à gestão integrada e ao gerenciamento de resíduos sólidos, incluindo os perigosos, as responsabilidades dos geradores e do poder público e aos instrumentos econômicos aplicáveis. (BRASIL, 20Io, p.I).

Essa lei é bastante atual, e é vista como um avanço no país por tratar de todos os resíduos sólidos (materiais que podem ser reciclados ou reaproveitados). Cria, metas e diretrizes relativas à gestão e gerenciamento de resíduos sólidos. Exige dos setores públicos e privados a transparência no gerencialmente de seus resíduos e obriga os fabricantes e as demais empresas que comercializam aparelhos eletrônicos a recolherem e dá a destinação correta aos seus resíduos eletrônicos para minimizar os danos ambientais. A lei ainda menciona que sejam extintos os lixões a céu aberto.

Antes do decreto da PNRS, como não existiam leis sobre a destinação do lixo eletrônico, e as empresas de manufatura não eram responsabilizadas pela destinação dos seus resíduos, depois de utilizados pelos clientes, todos esses resíduos eletrônicos eram jogados em aterros a céu aberto junto ao lixo urbano sem receber nenhum tipo de tratamento.

$\mathrm{O}$ artigo $30^{\circ}$ diz que:

[...] a responsabilidade compartilhada pelo ciclo de vida dos produtos, a ser implementada de forma individualizada e encadeada, abrangendo os fabricantes, importadores, distribuidores e comerciantes, os consumidores e os titulares dos serviços públicos de limpeza urbana e de manejo de resíduos sólidos.

Segundo o artigo $9^{\circ}$ da lei 12.305/2010, na gestão e gerenciamento de resíduos sólidos, deve ser observada a seguinte ordem de prioridade: não geração, redução, reutilização, reciclagem, tratamento dos resíduos sólidos e disposição final ambientalmente adequada dos rejeitos. A única forma de disposição final permitida no Brasil é o Aterro Sanitário.

Essa lei foi criada, visando melhorar os processos de destinação dos resíduos e diminuir os impactos ambientais. Apesar da obrigatoriedade da lei, pouco tem sido aplicada no Brasil, os lixões a céu aberto que deveriam ter sido extinto desde 2014, ainda existem. Somente $4 \%$ dos resíduos 
eletrônicos gerados, tem o tratamento correto. Diante disso o Brasil para tentar mitigar o problema do lixo eletrônico Depois de quase io anos desde a criação da PNRS, foi assinado um novo decreto no dia 12 de fevereiro de 2020, o decreto n. ${ }^{\circ}$ 10.240/20, que implementa o sistema de logística reversa de produtos eletroeletrônico doméstico em todo território brasileiro. $\mathrm{O}$ novo decreto objetiva a estruturação e a implementação de sistema de logística reversa de eletroeletrônicos de uso doméstico de serviços de saúde. Nesse novo decreto não inclui as pilhas, baterias ou lâmpadas dos produtos eletroeletrônicos, pois, estes não estão incluindo nas grandes quantidades de resíduos.

De acordo com Ministério do Meio Ambiente, "O decreto era o que faltava para estruturar o sistema e o cidadão ter onde levar e ter quem destine o material a locais adequados para o desmonte e a reciclagem". Com isso esperasse que até 2025 sejam criados 5 mil pontos de coleta de lixo eletrônico através disso (17\%) do lixo eletroeletrônico pode ser reciclado.

\section{ISO I400I}

A ISO é uma organização não governamental formada por diversos países, fundada em Genebra, na Suíça, no ano de 1947. Estabelece normas técnicas de todos os campos em quase todo o mundo. Uma das normas mais conhecida que visa o "manejo ambiental" é as das séries ISO, I40or.

A ISO I40or é uma maneira de se adequar à Política Nacional de Resíduos Sólidos. Pois, exige que as fabricantes de resíduos se comprometam com a prevenção da poluição e preservação do meio ambiente.

Oferece diretrizes e parâmetros para o desenvolvimento e implementação de sistemas de gestão ambiental nas empresas.

\section{DESCARTE E REUTILIZAÇÃO DO LIXO ELETRÔNICO}

O lixo eletrônico por conter em sua composição algumas substâncias perigosas. Deve ser reciclado de forma cuidadosa por pessoas especializadas. De acordo com a Lei 12.305/10 que obriga as empresas a coletarem seus resíduos eletrônicos. Com isso os fabricantes ficam responsáveis por separar os componentes, e dá a destinação adequada aos seus resíduos sólidos.

Hoje, grandes fabricantes de produtos eletrônicos, como Dell e a Apple, possuem sistema de coleta dos seus resíduos. Algumas operadoras de celulares no Brasil têm pontos de coletas de baterias e aparelhos em suas lojas.

Para Celinski et al. (20II, p.3): 
[...] Existem três maneiras para o destino do lixo eletrônico. A primeira ação está relacionada aos equipamentos que possuem, ainda algum tempo de vida, esses poderiam ser utilizados pela comunidade em projetos de inclusão digital. A segunda está voltada para o descarte das partes que são obsoletas, que podem ter seus componentes reutilizados e reciclados. A terceira seria a conscientização da população por meios de palestra, criação de postos de coletas, visando a importância da reciclagem do lixo eletrônico para a sustentabilidade do seu ciclo de consumo.

Uma das alternativas para evitar e diminuir os impactos causados pelo lixo eletrônico é a reciclagem dos resíduos eletrônicos.

A reciclagem consiste em uma série de atividades que se inicia com a coleta do lixo eletrônico através dos canais reversos. Logo após os aparelhos são desmontados e passam por um processo de remanufatura reversa. Cada material é separado. Com as peças devidamente separadas, torna-se possível dar a correta destinação a cada tipo de componente dos aparelhos. Depois acontece a trituração, com isso cada elemento é destinado a um fim. Em alguns casos são possíveis reciclar até I00\% dos materiais. Um exemplo disso é o Japão, que utilizará metais recuperados a partir da reciclagem de resíduos eletroeletrônicos, mais conhecido como lixo eletrônico, como matéria-prima para a confecção das medalhas olímpicas de ouro, prata e bronze para os jogos que aconteceriam no ano de 2020.

Outra forma de usar o lixo eletrônico é através do reuso, ou seja, o material não vai se transformar em algo novo, mas passa por um processo de desmontagem, seus componentes passam por uma limpeza, reparação se preciso for trocada as peças danificadas e é remontado. Além de contribuir com o meio ambiente, economiza energia e matéria-prima.

\section{METODOLOGIA}

A metodologia utilizada para o desenvolvimento do estudo em questão foi sistemicamente em forma de pesquisa bibliográfica e documental, com intuito de entender como o como a logística reversa pode auxiliar na diminuição dos impactos ambientais. Portanto, foi feita uma pesquisar em vários artigos científicos eletrônicos, livros dos principais autores que falam sobre o tema e notícias em sites sobre o problema do lixo eletrônico. Foram pesquisadas palavras chaves como 'logística reversa", "o uso da logística reversa' 'lixo eletrônico", "impactos ambientais causados pelo lixo eletrônico" e "lei PNRS". 
Fonseca (2002) diz que a pesquisa bibliográfica é feita a partir do levantamento de referências teóricas já analisadas, e publicadas por meios escritos e eletrônicos, como livros, artigos científicos, páginas de web sites. Qualquer trabalho científico inicia-se com uma pesquisa bibliográfica, que permite ao pesquisador conhecer o que já se estudou sobre o assunto.

O método de abordagem utilizado na pesquisa será o método dedutivo. Que ser baseará em teorias e leis que já existem.

\section{LOCAL DA PESQUISA}

Porto velho é a capital do estado de Rondônia. Localizada na região norte do Brasil. Com uma população de 529544 habitantes, conforme estimativas do Instituto Brasileiro de Geografia e Estatística (IBGE/2019). Fundada em 04 de junho de 1907. Pela empresa Americana Madeira Mamoré Railway Company.

\section{COLETA DE DADOS}

No que tange a coleta de dados da pesquisa. A primeira parte aconteceu através de dados secundários artigos e notícias em sites. $\mathrm{Na}$ segunda parte da pesquisa realizou-se um questionário online contendo seis perguntas (duas questões abertas e quatro questões fechadas) com uma pequena amostra de pessoas de diferentes bairros da capital do município de Porto Velho. Esse questionário e gráficos foram criados através do Google Forms, no dia 16 de maio de 2020 e ficou aberto até o dia 22 de maio do mesmo ano. Com intuito de obter respostas acerca do conhecimento da população sobre o lixo eletrônico. Segue abaixo o modelo de questionário aplicado.

\section{QUESTIONÁRIO SOBRE LIXO ELETRÔNICO}

I. Em que bairro do município de Porto Velho você mora?

2 Você sabe o que é lixo eletrônico?

( ) Não. É a primeira vez que ouço falar.

( ) Já ouvi falar. Mas não sei exatamente.

( ) Sim. Conheço.

2. Onde você costuma jogar seus aparelhos eletrônicos?

( ) Lixo comum.

( ) Devolve para a empresa onde adquiriu. 
( ) Encaminhou para alguma empresa de reciclagem.

3. Você já ouviu falar sobre logística reversa?
( ) Sim
( ) Não

3 Você conhece alguma empresa que recicle o lixo eletrônico?

( ) Sim ( ) Não

4 Pra você qual seria a melhor forma de descartar o lixo eletrônico?

RESULTADOS

Este capítulo tem como objetivo apresentar e discutir os resultados obtidos através do questionário online. E, ao final, propor uma solução para minimizar os efeitos negativos do lixo eletrônico no município de Porto Velho.

\section{RESULTADO DO QUESTIONÁRIO ONLINE}

Através questionário online. Foi possível obter os seguintes dados. O gráfico I, demonstra os bairros do município de Porto Velho, onde foram coletados os dados.

Gráfico I- Resultado da pergunta i “Em que bairro do município de Porto Velho você mora?”. 


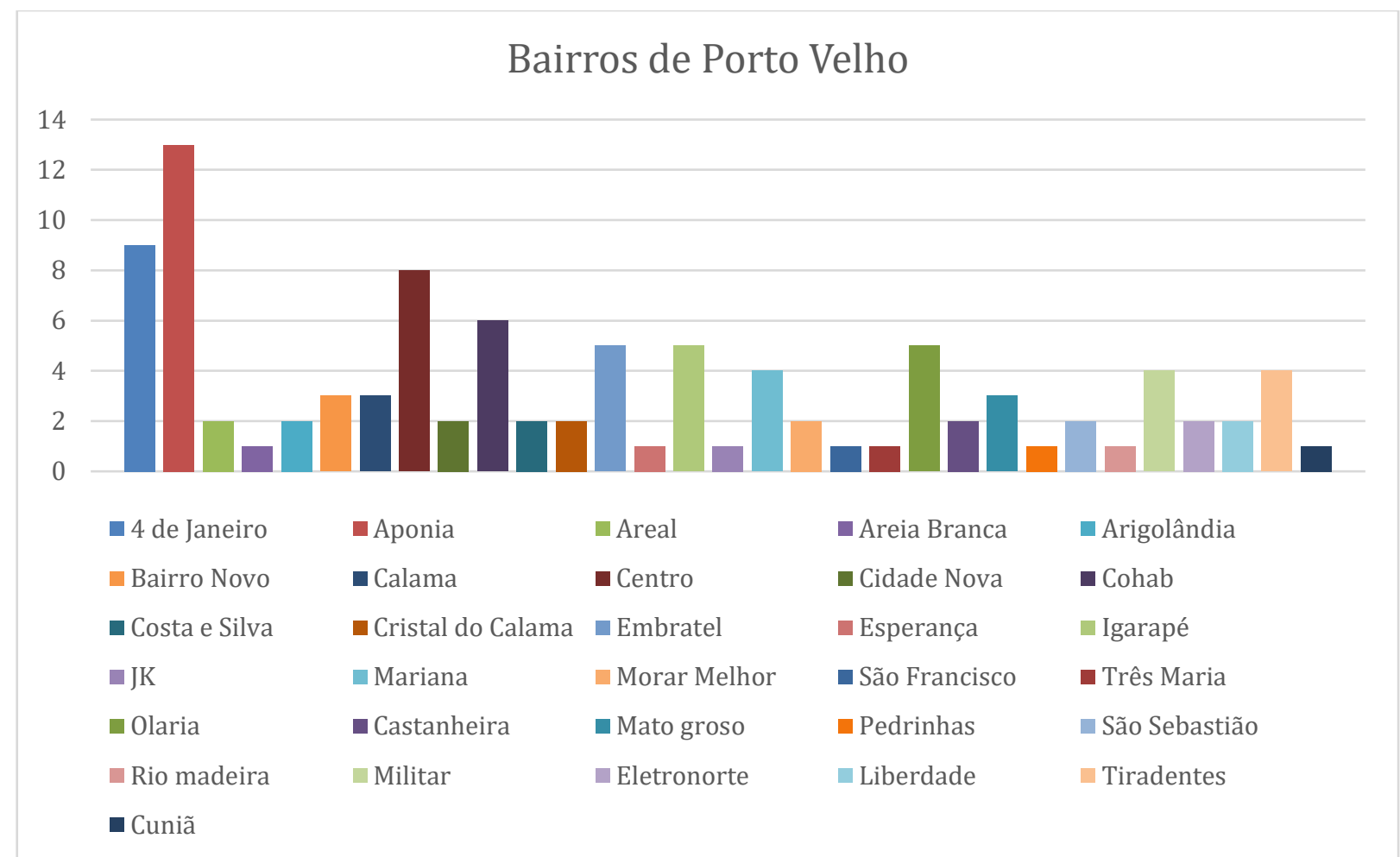

Fonte: Elaborado pela autora em (2020)

No gráfico 2, quando questionados sobre o que era lixo eletrônico, $64 \%$ dos respondentes não sabia do que se tratava. Somente I2\% tinham conhecimento sobre o assunto.

Gráfico 2- Resposta da pergunta 2 "Você sabe o que é lixo eletrônico?".

Você sabe o que é lixo eletrônico?

100 respostas

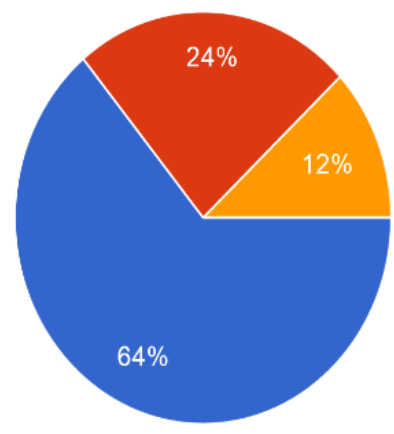

Não. É a primeira vez que ouço falar.

Já ouvi falar. Mas nao sei exatamente.

Sim. Conheço. 
No gráfico 3, percebe-se que grande parte das pessoas desconhecem os perigos que os resíduos eletrônicos podem causar ao meio ambiente e acabam descartando seus aparelhos eletrônicos junto ao lixo comum.

Gráfico 3- Resposta da pergunta 3 “Onde você costuma jogar seus aparelhos eletrônicos?”.

Onde você costuma jogar seus aparelhos eletrônicos?

100 respostas

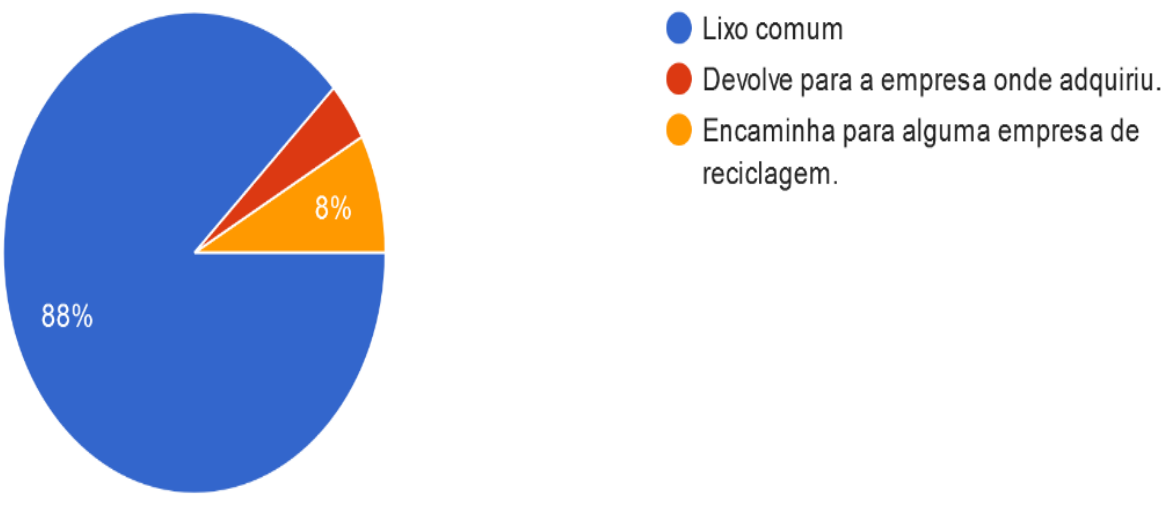

Através dos gráficos 4 e 5 , percebe-se que há pouco empenho dos setores públicos no gerenciamento do lixo eletrônico, pois boa parte da população desconhece que através da remanufatura reversa os resíduos eletrônicos podem ser reciclados, evitando assim a poluição do ambiente. 
Gráfico 4- Resposta da pergunta 4 "Você já ouviu falar sobre logística reversa?". Você já ouviu falar sobre logistica reversa 100 respostas

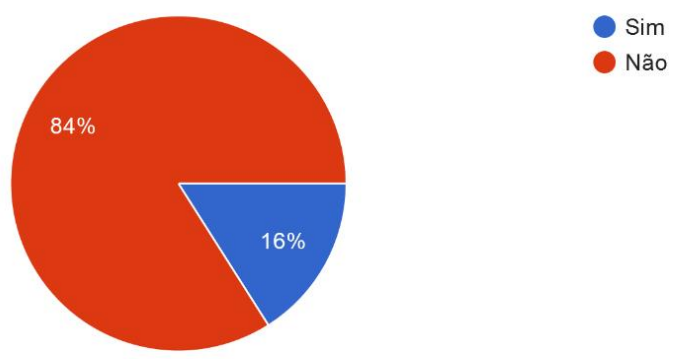

Gráfico 5 -

Resposta da pergunta 5 "Você conhece alguma empresa que recicle o lixo eletrônico?".

Você conhece alguma empresa que recicle o lixo eletrônico?

100 respostas

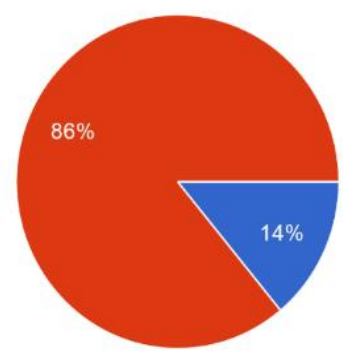

\section{PROPOSTA DE UMA COOPERATIVA DE RECICLAGEM DE RESÍDUOS ELETRÔNICOS}

O município de Porto Velho gera em torno de 19 mil toneladas de lixo por mês, entre esse lixo, boa parte corresponde aos resíduos eletrônicos. Por falta de empresas de reciclagem e de coleta seletiva na cidade, grande parte desses resíduos eletrônicos são descartados a céu aberto sem receber o tratamento correto. Outra parte desse lixo vai parar no lixão da capital, que recebe em torno de 450 toneladas de lixo por dia.

Com o propósito de mitigar o problema do lixo eletrônico no município de Porto Velho. Buscou-se apresentar uma solução para esse problema. Que consiste na criação de uma cooperativa de reciclagem, uma vez que, resíduos sólidos geram recursos e empregos. Além de minimizar os impactos que o lixo eletrônico causa ao meio ambiente. As empresas de reciclagens podem injetar até $\mathrm{R} \$ 700$ milhões na economia brasileira. 
Uma cooperativa de reciclagem de resíduos eletrônicos oferece um serviço de logística reversa dos produtos eletrônicos. Diante disso a proposta de uma cooperativa de reciclagem inicialmente começaria com foco na coleta e separação dos resíduos eletrônicos. Com vários pontos de coletas espalhados pela cidade.

\section{CONCLUSÃO}

A tecnologia vem evoluindo muito rapidamente, com isso os produtos que adquirimos hoje acabam tendo uma vida útil mais curta, comparados com os de antigamente. Esse avanço tecnológico traz consigo um grande problema que é o lixo eletrônico. Quando substituímos nossos produtos eletrônicos por outros mais novos, produzimos um extenso volume de lixo eletrônico, que na maioria das vezes são descartados de maneira inadequada causando enormes prejuízos ao meio ambiente.

A presente pesquisa buscou avaliar a questão do uso da logística reversa no tratamento do lixo eletrônico. Com o objetivo mostrar um conceito geral sobre a logística reversa e como a logística reversa pode auxiliar na diminuição dos impactos ambientais causados por esse lixo. Para atingir os objetivos da pesquisa buscou-se apresentar os impactos negativos do lixo eletrônico ao meio ambiente e entender mais sobre a Política Nacional dos Resíduos Sólidos, uma lei que foi um grande avanço na questão ambiental. Que trata dos resíduos sólidos, em geral, e no artigo 33, dá ênfase sobre a responsabilidade no gerenciamento do lixo eletrônico, onde diz que as empresas e fabricantes ficam responsáveis pela logística reversa dos seus produtos. Partindo dessa lei foi apresentado também a lei do município de Porto Velho $\mathrm{n}^{-}$2138, a qual institui normas e procedimentos para a coleta e destinação final dos produtos eletroeletrônicos.

Para obter dados quantitativos na pesquisa foi realizado um questionário, com seis perguntas. O qual pretendia coletar informaç̃̃es da população de Porto Velho sobre o lixo eletrônico. Os resultados apontaram que a maioria das pessoas desconhece o termo lixo eletrônico e os descarta junto ao lixo comum em casa. Constatou-se ainda que mais de $80 \%$ dos respondentes desconhecem a existência de alguma empresa de reciclagem de resíduos eletrônico.

Com a finalização dessa pesquisa, conclui-se o lixo eletrônico é um problema recorrente em todo Brasil, e que ainda não possui grande atenção da sociedade. Apesar de existe a lei PNRS, que completará io anos em agosto. Pouco ou quase nada progrediu. 


\section{REFERÊNCIAS}

AFFOSON, J.C. Semana da Inclusão Digital discute os 50 milhões de toneladas do lixo eletrônico. 2008. Disponível em: http://telebrasil.org.br/artigos/outros_artigos.asp?m725>. Acesso em: II/O5/2020.

BRANDALISE, L.T. A percepção do Consumidor na Análise do Ciclo de Vida do produto: um modelo de apoio à gestão empresarial. Cascavel: EDUNIOESTE, 2009.

BRASIL BBC. Países pobres são destino de $80 \%$ do lixo eletrônico de nações ricas. Brasília, 2013. Disponível em: https:bbc.com/portuguese/noticias/2013/or/r30II8_lixo_eletronico_bg.shtml. Acesso em 22/03/2020.

BRASIL. Lei n. 12.305, de 2 de agosto de 2010. Política Nacional de Resíduos Sólidos. Disponível em: http://planalto.gov.br. Acesso em: II/o4/2020.

BRASIL, D.M. Comércio eletrônico: a popularização no setor bancário. 20II, 53f. Monografia (Bacharelado em Administração) - Universidade de Brasília. Brasília, 20 Ir.

CARVALHO, T.C.M.B. XAVIER, L.H. Gestão de resíduos eletrônicos. I. Ed Rio de Janeiro: Elsevier, 20I4.

CELINSKI, T.M.; CELINSKI, V.G.; GHIZZI, H.; FERREIRA, J.S. Perspectivas para reuso e reciclagem do lixo eletrônico. In: Congresso Brasileiro de Gestão Ambiental, 2., 2oII, Londrina, Anais[...]. Londrina: IBEAS, 20II.

CHAVES, G.L.D.; MARTINS, R.S. Diagnóstico da logística reversa na cadeia de suprimentos de alimentos processados no oeste paranaense. In: VIII Simpósio de Administração da Produção, Logística e Operações Internacionais (SIMPOI), ago. 2005, São Paulo. Anais...São Paulo: FGV, 2005. FERREIRA, J.M.; FERREIRA, A.C: A Sociedade da informação e o desafio da sucata eletrônica. Revista de ciências exatas e tecnologia. Vol. III, n.3, 2008.

FONSECA, J. J. S. Metodologia da pesquisa científica. Fortaleza: UEC, 2002. Apostila. GONÇALVES, A.T.O. O lado obscuro da high tech na era do neoliberalismo: seu impacto no meio ambiente. In: http://lixotecnológico.blogspot.com. Acesso em: 22/03/2020.

JORNAL DA CIDADE DE BAURU. Crescimento do lixo eletrônico ameaça à saúde da população. Bauru-SP. 2012.

LABIDI, S. Lixo eletrônico. 20II. Disponível em www.jornalpequeno.com.br/e-lixoI87844print.htm/ Acesso em: 03/05/2020. 
LEITE, P. R. Logística Reversa: meio ambiente e competitividade. r.ed. São Paulo: Prentice Hall, 2003.

MACEDO, R.L.G. Percepção e Conscientização Ambientais. Lavras: UFLA - Universidade Federal de Lavras/ FAEPE - Fundação de Apoio ao Ensino, Pesquisa e Extensão, 2000.

NOVAES, A.G. Logística e gerenciamento da cadeia de distribuição: estratégia, operação e avaliação. 3.ed. Rio de Janeiro: Campus, 200I.

POLÍTICA NACIONAL DE RESÍDUOS SÓLIDOS. Disponível em: http://www.camara.gov.br/sileg/integras/501911.pdf> Acesso em: II/04/2020.

PORTO VELHO. Lei Municipal n. 2138, de 26 de março de 2014. Institui normas e procedimentos para coleta, armazenagem e destinação final de eletrodomésticos e produtos eletroeletrônicos considerados como lixo tecnológico, no âmbito do Município de Porto Velho. Porto Velho, RO. Disponível em: http://leismunicipais.com.br/a/ro/p/porto-velho/lei-ordinaria/2014/214/2138/leiordinaria-n-2138-2014-institui-normas-e-procedimentos-para-a-coleta-armazenagem-e destinacaofinal-de-eletrodomesticos-e-produtos-eletroeletronicos-considerados-como-lixo-tecnologico-noambito-do-municipio-de-porto-velho. Acesso em: 10/05/2020.

RIBEIRO, R. R. M. Evolução das pesquisas em Contabilidade Gerencial: uma análise das opções temáticas e abordagens metodológicas no Brasil. 20II. I2of. Dissertação (Mestrado em Contabilidade), Programa de Pós-graduação em Contabilidade, Universidade Federal do Paraná, Curitiba, 20II.

RODRIGUES, P.R.A. Introdução aos sistemas de transporte no Brasil e a logística internacional. 4.ed. São Paulo: Aduaneiras, 2007. 